\title{
Effective Adoption of Tablets in Post-Secondary Education: Recommendations Based on a Trial of iPads in University Classes
}

\author{
Colin F. Mang and Leslie J. Wardley \\ Nipissing University School of Business, \\ North Bay, Ontario, Canada \\ colinm@nipissingu.ca lesliew@nipissingu.ca \\ Executive Summary
}

This paper explores the integration of tablets, such as the Apple iPad, in university classes and provides recommendations for other instructors to consider when adopting tablet technology. During the trial conducted in the summer of 2011 using iPads, we found that tablets had both academic and social uses, which should be considered when using this technology.

The key to successfully adopting tablet technology was to ensure that students remained academically engaged with the device on a regular basis so that they became accustomed to its use. We found that the most useful ways to encourage academic engagement with the device included taking notes during lectures and conducting research during class. The connectivity associated with the devices allowed for enhanced interaction and collaboration among the students. We also found that tablets posed much less of a distraction to students than laptops, i.e., students who used tablets were less likely than laptop users to engage in off-task activities such as instant messaging, social network usage, and watching videos during a lecture.

We make five recommendations for faculty who are considering adopting tablets as a mandatory component in their classrooms:

1) Know "everything" about the tablet operating system prior to distributing tablets to your students.

2) Decide early on how you would like to use the tablet in your class.

3) Ensure that you work closely with your institution's Information Technology department.

4) Make the tablet an integral component of your class.

5) Describe the features and benefits on the first day.

6) Carefully consider how to distribute the tablets.

Material published as part of this publication, either on-line or in print, is copyrighted by the Informing Science Institute. Permission to make digital or paper copy of part or all of these works for personal or classroom use is granted without fee provided that the copies are not made or distributed for profit or commercial advantage AND that copies 1) bear this notice in full and 2) give the full citation on the first page. It is permissible to abstract these works so long as credit is given. To copy in all other cases or to republish or to post on a server or to redistribute to lists requires specific permission and payment of a fee. Contact Publisher@InformingScience.org to request redistribution permission.
Keywords: higher education, iPad, mobile technology, tablet 


\section{Introduction}

As mobile technology develops, it creates new opportunities for enhancing the learning experience of students at all levels of education. In this paper we explore the adoption of tablet devices, a relatively new consumer product, in post-secondary education. Although tablet personal computers have existed for some time, Weider (2011) noted that their size and cost proved prohibitive to adoption by educators, and by consumers generally. It has only been since 2010 that portable, easy-to-use, and relatively inexpensive tablets have become widely available. The current market leader in tablet technology is the iPad produced by Apple; however, competing technologies, including Samsung's Galaxy Tab, which uses Google's Android operating system, and Blackberry's Playbook, provide similar functionality.

Already, a number of institutions have experimented with universal adoption, i.e., where every student in a particular course or program is given a tablet to use in class. The increasing popularity of these devices will likely lead to even greater adoption among students at the post-secondary level over the coming years; however, adopting technology for technology's sake does not guarantee improved learning outcomes or an enriching educational experience (Murphy, 2011). On the contrary, several attempts at North American institutions to adopt tablets have been unsuccessful. It is therefore critical for faculties who are considering universal adoption of tablet technology to be aware of the potential issues that can arise so they can prepare strategies to ensure successful use of the tablets in class.

The key to successfully adopting tablets is to ensure that the devices are integrated into both the academic and the social aspects of the course (Franklin, 2011). In a pilot study conducted in 2011, we explored the potential academic uses for a tablet, including viewing and taking lecture notes, reading textbooks and articles, conducting research, and completing electronic assessments such as quizzes; as well, we explored the use of the devices for social purposes, such as enhancing interaction and collaboration among the students. Therefore, the purpose of this study was to identify potential uses for tablets in university classes and to identify any difficulties associated with using tablets in a class. Our department has in the past considered adopting laptop computers as a required tool in classrooms to enhance interaction among and "real-time" researching by students; however, the new tablet technology presented an alternative for us to explore.

This paper will begin with a brief discussion of studies dealing with technology use in classrooms as well as discussions of other recent trials specifically using tablets in university classes. We then discuss our experiences successfully integrating the use of Apple iPads into our classes and provide specific examples of academic and social uses for the devices, which can enhance the learning experience. We provide recommendations for other instructors who are considering adopting tablet technology. Finally, we close with what we found to be the differences between using tablets and using laptops in the classroom.

\section{Literature Review}

A wide variety of studies have explored the integration of emerging technologies in the classroom. For example, Banister (2010) reviewed the literature on mobile technology in K-12 education and also provided recommendations on integrating iPod Touch devices in primary and secondary school classrooms. Much research has also been conducted on the use of laptop computers in higher education. For example, Cismaru and Cismaru (2011) provided an overview of the use of laptop computers in Canadian universities. Kay and Lauricella (2011a, 2011b) found that laptops provided benefits, including improved note-taking, improved organizational skills, and improved collaboration among students; however, they also found that laptop use posed challenges including distractions caused by students using instant messaging applications, playing games, and watching movies instead of focusing on the class. Also, Percival and Percival (2009) ex- 
plored perceptions and usage of laptops in a mandatory campus-wide laptop program and found that, for laptop use to be most effective, individual academic programs must develop their own strategies for implementation. They determined that proposing a single learning model for all disciplines is not optimal; it should be the subject matter of the courses that determines how best to integrate the technology. Furthermore, Vuojärvi, Isomäki, and Hynes (2010) explored the relative ease/difficulty that students in laptop mandated programs had in integrating the laptop into their personal and academic lives; they found that students who had a higher proficiency with information technology, and especially those who had prior experience with the software used in class, were quicker to adopt the laptop as both a learning tool and a personal tool. However, our focus was on the integration of tablet technology. Because the technology had only recently become available, Gawelek, Spataro, and Komarny (2011) acknowledged that there was only a small amount of literature surrounding the academic applications of this technology. Most studies so far, like our own, had focused on the Apple iPad, which was the first "new" tablet to come to market.

Goral (2011) detailed the main advantages of using tablet technology: using software applications to enhance creativity and critical thinking, using digital texts and readings which lead to substantial cost savings for students, and encouraging greater interaction among students and faculty. A number of institutions had experimented with the use of tablet technology in their programs. Kaya (2010) reported that pilot trials using iPads had been tried at Seton Hill University and Long Island University, while Keller (2011) similarly reported on the use of iPads at Stanford University's School of Medicine. At the time of writing, a pilot is currently underway at the University of Southern Mississippi, using a competing technology: Samsung's Galaxy Tab tablet ("University of Southern", 2011). Benefits of using the tablet have included a reduction in the amount of paper used and a reduction in textbook costs as students have opted for electronic versions of the text. However, Fischman and Keller (2011) indicated that the trials of iPads at Stanford and in a University of Notre Dame management class were not successful as many students were uncomfortable with the technology and abandoned its use within a few weeks in favor of more traditional technologies such as laptops.

The main drawbacks of tablet technology include the difficulty of typing on the "keyboard," which is simply projected on the lower portion of the screen, and also the difficulty of writing or drawing with one's finger-tip. Fischman and Keller (2011) and Wieder (2011) cited these two issues as being among the primary reasons the trials at Stanford and Notre Dame were unsuccessful. However, note that physical keyboards and styluses for handwriting are now available for many types of tablets, thus resolving some of these issues. Nevertheless, Weider (2011) noted that tablet use offered distinct advantages; they improved student-to-student collaboration among calculus students at Pepperdine University where students were able to work together and share screen images while solving problems, and they improved students' ability to make reference to course readings during class discussions at Reed College. Eichenlaub, Gabel, Jakubek, McCarthy, \& Wang (2011) also reported increased collaboration and improvements in organizational skills and research skills among students using tablets at Ryerson University. Also important, BizEd Magazine ("Schools Release iPad Studies", 2011) reported that $75 \%$ of students at Oklahoma State University believed the tablet improved their learning, and 97\% indicated they would prefer to continue taking classes that integrated tablet technology.

What is clear from the literature is that the integration of tablets in a post-secondary setting is not guaranteed to be successful. Based on their experiences at Seton Hill, Gawelek et al. (2011) determined that strong leadership among the institution's senior administration is necessary to encourage faculty to adopt the device. As well, the trials reported in the literature to date demonstrated that most students would not simply adopt the device voluntarily; rather, students must see a "need" for sustained interaction with the device. 


\section{Using Tablets in Our Classes}

We chose to test the viability of using tablet technology in post-secondary education by conducting a small pilot study in the summer of 2011. We selected three summer courses being offered over a four to six-week period and provided each student an Apple iPad to use for the duration of the course. We selected the iPad for the following reasons:

1) both of us were already familiar with the iOS operating system used on the iPad because of our experiences with other Apple devices (iPods, iPhones);

2) anecdotal evidence, and observations of students in other classes suggested that many of the students were already familiar with the iOS operating system from using iPods or iPhones, and we felt that fact would make the transition to use of the technology easier, given Vuojärvi et al.'s (2010) assertion that previous experience with software leads to quicker adoption and integration;

3) iPad "App Store" purchases could be shared among multiple Apple devices, so students who already owned iPods or iPhones could use applications across the platforms. Thus, if they decided to purchase any applications for use on the iPad, they could still maintain access to those applications after returning their iPad at the end of the trial;

4) the iPad was the market leader, the most popular tablet at the time with approximately 68\% market share ("Apple can run", 2011), and other institutions had begun to experiment with it as well so our findings could be better compared with outcomes from other academic institutions;

5) at the time, there were too many inconsistencies among the android system devices, i.e., variances in support networks and manufacturing specifications.

Total enrollment in the three courses was 49 students; however, as two students were enrolled in multiple courses, the total number of students receiving an iPad was 47 . We chose the summer semester primarily because of the smaller class sizes relative to the fall and winter semesters, which reduced the overall number of iPads required. The smaller class size also ensured that we would be able to give each student individual attention if they experienced problems with their device. In addition, we had each taught numerous summer semester courses previously, so were in a position to directly compare our classroom experiences in those courses with and without tablets. One of the courses was an introductory Organization Behavior course, comprised primarily of theoretical discussion and application; one was a second-year Ethics course comprised largely of normative discussion and debate, while the third course was a second-year Economics course, which focused on positive mathematical analysis. The diversity of course content helped us to assess the tablet's application to both quantitative and qualitative subjects.

As none of the 47 students owned an iPad prior to the course, we provided iPads to the students at no charge to them; however, students were required to sign a user agreement requiring the iPads to be returned undamaged at the end of the semester. For two of the courses, students were told in advance that iPads would be used, and that they would be provided to students who did not already have one. However, we did not inform potential registrants that the third class would also be using iPads; rather we simply surprised those students on the first day of class. Because the students did not know in advance that the course would be using iPads, we were sure that any possible apprehension at using the technology would not be a deterrent to students registering in that class. We provided the students with base model iPads with 16 gigabytes (GB) of storage capacity. We felt that the expanded storage capacity (32GB or 64GB) and cellular network access capability of the advanced iPad models was unnecessary; such features would only be useful if 
the students needed to store a very large amount of multimedia content or if they needed an internet connection in an area without Wi-Fi service.

Our efforts to utilize the tablet were two-fold. First, we sought methods that would integrate the use of the tablet into the academic components of the course. Second, realizing the opportunities that the connectivity of the tablets could bring, we also focused on methods of social integration, using the tablets to encourage enhanced communication and interaction between the students.

\section{Academic Integration - Tablet-Format Lecture Notes}

The primary purpose of using iPads in the classroom was to enhance the academic experience of the students. Through the period of our trial, we experimented with a variety of different strategies for making use of the technology in the classroom. We realized that students would use the tablet for both "structured use" activities, in which they had specific tasks related to the class to perform with the device, and "unstructured use" activities, in which they could choose how, or whether, to use the device - of course, unstructured use could include using the device for personal activities in addition to, or even instead of, using it for academic purposes. To prevent the tablet from becoming a distraction which hindered learning in the way that Kay and Lauricella (2011a, 2011b) reported that laptops became, we sought to engage the students with as many structured use activities as possible.

The most basic use we identified for the tablet was in taking lecture notes through the session. When creating our lectures, we focused on creating lecture templates which could be easily distributed to the students and serve as a basis for taking lecture notes electronically on the tablet rather than recording them with a pen and paper. We distributed lecture note templates in portable document format (pdf) for each lecture session; the notes mimicked the lecture slideshows that we projected. Through the use of a free application that allowed students to make annotated notes on top of an existing pdf file, the students were able to record any additional notes they wanted to make directly over top of the lecture template. For one course, taking lecture notes would require the drawing of graphs. As the typical student would need sufficient space to draw the graph, lecture note slides which required the drawing of graphs would have about $50 \%$ of the space on the

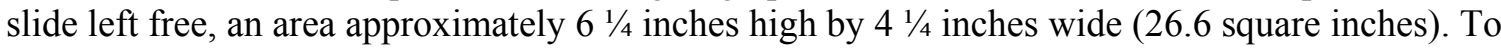
ensure easy readability, we used a minimum $26 \mathrm{pt}$ font in all slides. As well, we purposely also left some available space on each slide for students to enter typed notes or handwritten explanations. Figure 1 provides an example of a slide including a hand-drawn graph and additional handwritten annotation. Figure 2 provides an example of a lecture slide with additional space left for notes. 
Unit 2: Supply and Demand Analysis How Supply Affects the Market

- A rise in input prices will increase production costs and shift the supply curve upward. The market price will rise as a result and the quantity sold will decrease.

$$
\begin{aligned}
& \text { Marginal cost is higher } \\
& \text { so firms need a higher } \\
& \text { price at each quantity sold }
\end{aligned}
$$

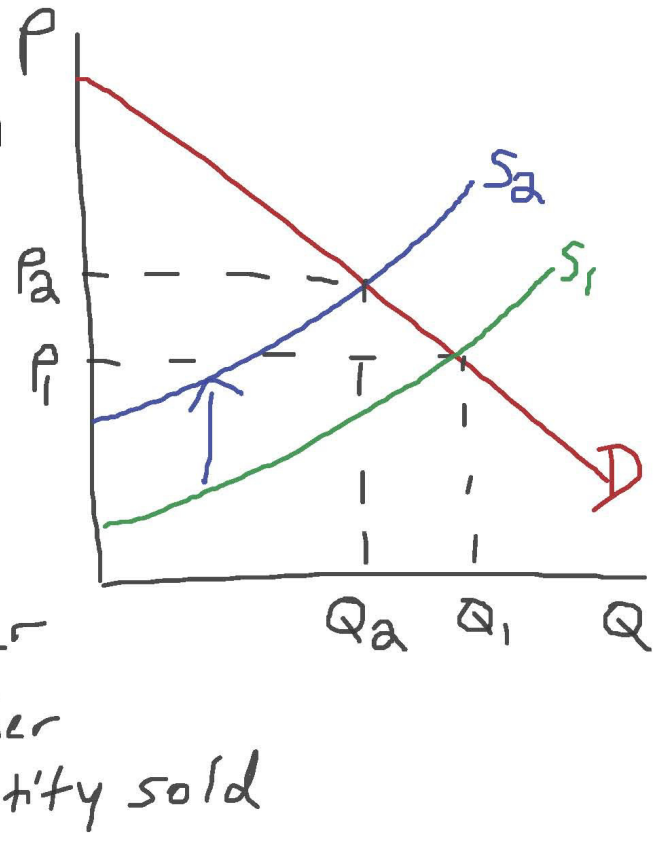

Figure 1: Example of an Annotated Lecture Slide with a hand-drawn graph

Motivation - Expectancy Theory

Please complete the model below by indicating the managerial actions that are required to connect the components of the model ie: what actions does a manager take to link - effort to performance, etc.

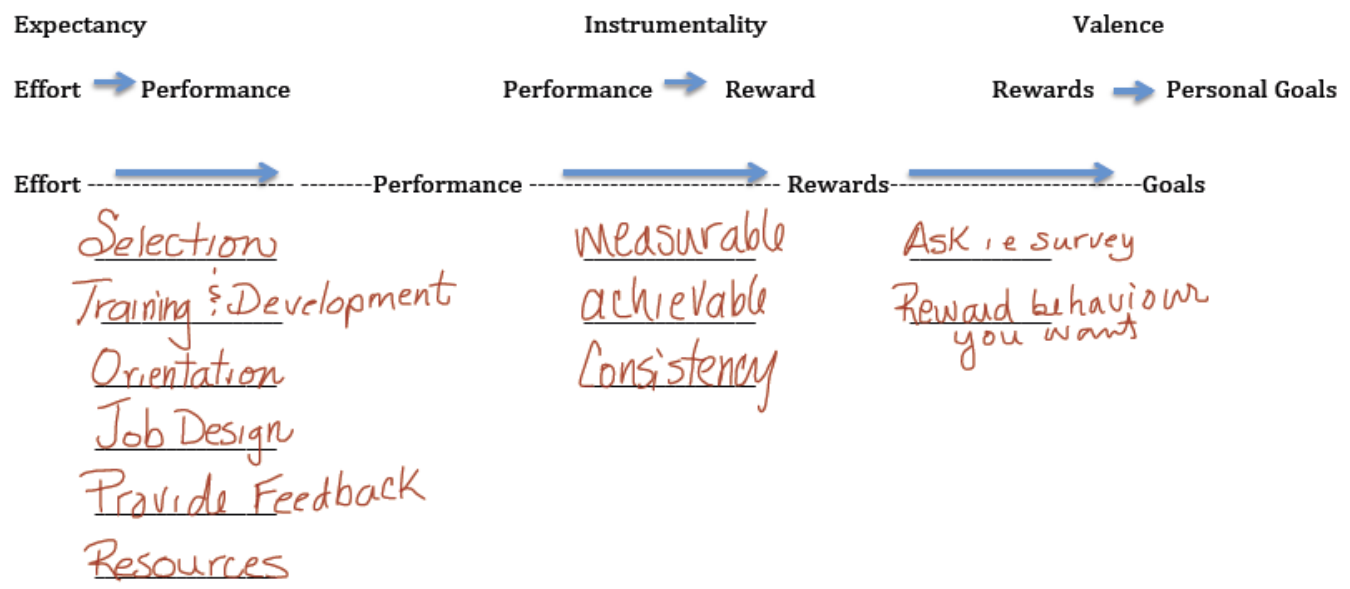

Figure 2: Example of an Annotated Lecture Slide 
Those instructors who regularly make their lecture notes available online prior to a class are quite accustomed to students printing out those notes, bringing them to class, and then adding their own notes on top of them. Using a tablet, such as the iPad, and pdf lecture files represented an efficiency improvement over that activity since (a) the students did not need to spend time or resources printing the notes, the cost of which can become considerable over the course of an entire semester; (b) the students did not need to carry around a stack of paper notes for the course; (c) the document remained in pdf format so the document could be saved and then accessed on any desktop computer, laptop, or tablet device. We recommended that students save a copy of each set of lecture notes in their email accounts, so that the notes would be accessible anywhere the student had an internet connection. Thus the student would never be in danger of losing these resources.

The pdf annotation application that we selected allowed users to type additional notes onto the original document; however, it also allowed users to make handwritten notes as well. This feature of allowing users to make handwritten notes was incredibly valuable, particularly in one of the classes which required a great deal of mathematical work including drawing graphs and solving equations. The ability to handwrite work, similar to the user handwriting on a piece of paper, substantially aided in the students' transition from creating paper notes to creating electronic notes. Because of the heavy mathematical component to one of the courses, and the fact that typing out mathematical equations is much more cumbersome than quickly handwriting them, the ability to record handwritten notes was a necessity for a complete migration to electronic notes.

An additional benefit of being able to handwrite over top of the existing lecture notes affected the entire delivery of the lecture material. Rather than using a laptop, or a lecture theatre's desktop computer, to project lecture notes onto the screen, as is common in many undergraduate classes, we both used our iPads to run our lecture presentations. Many lecturers, despite projecting a slideshow presentation, will often still write on the blackboard/whiteboard, or use an overhead projector with transparency films, or use an electronic document camera to project handwritten material onto the screen. The tablet eliminated the need for such activities, as handwritten annotations could be projected directly onto the screen during the presentation. This feature was particularly useful for using examples, which required drawing graphs and solving mathematical problems, as the instructor's handwritten notes could be projected immediately onto the screen without the need for switching to an alternative method for writing notes. Although, this method did require careful design of the lecture presentation slides to ensure there was sufficient blank space for both the instructor and the students to make their handwritten notes in the file.

Another use we found for the tablet was in distributing multimedia lecture content to the students through the creation of electronic publication format (ePub) documents which allowed video content to be integrated with standard text and graphics for in-class discussion. The use of ePubs created additional depth to the course content as we could divide the ePub into sections, which highlighted and tied the content to the desired learning objectives, and students could add searchable notations and highlighting to the documents using their iPads. Students could also link in-text words or topics to Internet sources for further information or content. This flexibility allowed the student to be able to tailor the content to suit their personal needs. However, the creation of ePubs proved to be restricted to the faculty level and did not become widely adopted among the students. Many students did not possess the software needed to create their own ePubs. Nevertheless, the students appreciated being given ePubs to read and interact with in class.

\section{Academic Integration - Research and Assessment}

Besides using the iPad to distribute lecture materials, we also made use of the iPad for a variety of other academic components in our classes. Many instructors often assign students a list of readings from journal articles and often bundle these readings into a printed "course-pack" which 
students must pay for, despite the fact that, in many cases, the university has a license allowing students to access the articles directly at no additional cost. Although we both assigned textbooks for our courses, we also each selected a variety of additional articles that were available electronically from our institution's library and showed students how to access the articles directly on their tablets.

As we had three distinctly different class structures, we were able to experiment with different teaching methods. Realizing that some students are inevitably unprepared for class and had not completed their assigned readings, we experimented with allotting a small portion of the lecture time to read a critical article for that week. Several times, we did not provide a list of readings in advance of the class, but rather prompted the students to look over relevant journal articles and newspaper articles once they arrived in class. We acknowledge that this strategy is only suitable for short journal articles and newspaper articles as students would likely not have sufficient time to digest a lengthy academic paper in the middle of a lecture. A discussion of the articles then followed with us assured that all the students had read the articles because we had observed them doing so. We found that, as all the students had completed the reading, it led to more active class participation in the discussions relative to what we had experienced in previous semesters, because all students were now prepared for the discussion. In another course, one of us also occasionally prompted students with topics for discussion, and then asked them to conduct research "on-the-spot" to find relevant articles that they could share with the class. This type of activity helped to greatly improve the students' research skills, as they became more accustomed to using electronic article databases. The fact that every single student had a device allowed us to integrate the teaching of research skills directly into the teaching of the course content, providing a wellrounded academic experience and assisting the students with practical skills development in addition to the traditional theoretical knowledge gained in lectures.

A final use we found for the iPads involved conducting electronic quizzes. Again it has become common for instructors to assign online quizzes for students to complete at home or to use some type of "clicker" technology in the class to conduct multiple choice testing. Because each student had a tablet, we were able to make use of both methods of quizzing during the lecture. One of us used a learning management system to distribute quizzes that the students completed using the iPad's web browser while the other used a software application that mimicked the use of "clickers". While the use of the tablet did not provide any improvement over the other technologies, the fact that all students had a tablet made conducting electronic quizzes in the lecture easier as the students did not need to bring another electronic device such as a clicker or a computer.

\section{Social Integration}

Besides the academic uses of the tablet, which we have identified, we also realized that the tablet could be used for a variety of social purposes as well. However, rather than allowing the students to use their iPads to physically isolate themselves behind a barrier of electronic communication, which can happen with unstructured use of the device, we designed a variety of activities in which tablets actually fostered enhanced face-to-face interaction. As noted above, we asked the students to use their iPads to conduct in-class research and then share the results with the class. Through the course of the discussions that ensued, we required students to continue researching to find additional information and alternative viewpoints. We encouraged the students to debate among themselves the various concepts covered in the lectures and to provide supporting evidence for their views based on information they were gathering in real time. The Internet access provided by the iPads allowed the students to challenge misleading facts and statements made by other students during the discussions, enhancing the dialogue within the classroom.

As well, one of us created specific group activities for the students to complete both during the lectures and between sessions. In previous classes, one of us had used group breakout exercises to 
allow students to discuss different questions connected to the lecture. The exercises were traditionally used as an informal way to encourage in-class student interactions and create familiarity among students. After completing the in-class discussion and reflection exercises in small groups, the students were normally asked to write their responses on the whiteboard/blackboard to facilitate a class debriefing of the outcomes and to allow students to record the other groups' answers. Through the use of the iPad, these same in-class group exercises were improved.

The students created their own documents, either though typewritten notes or cursive handwriting, in class, which were then shared with the class via the university's online learning manage-

ment system. This practice was efficient as more time was spent on the exercises because students had lasting electronic records of the class' collective work without the tedious and time consuming effort of recreating the notes themselves. However, there was an additional benefit of this process; students who were too inhibited to ask questions in class had the opportunity to contribute in their small groups and then share their thoughts with the class in a less threatening way. Their voices were heard without the need to be singled out by raising their hand and addressing the whole class or standing at the front of the room, which would have been required when writing on the blackboard/white board. Many students who initially expressed feelings of shyness in front of the class found they became more actively involved and less inhibited when speaking out in class once they realized that others also shared their views. As a result, this previously underrepresented group of students became active collaborators in the learning, and by extension the teaching, process.

The success of this method was expanded to include homework exercises. The students were asked to post their homework in pdf form behind the password-protected network so other students could view and make comments using annotative applications. This method of sharing improved the class contribution surrounding some topics, which had traditionally been stifled due to the sensitive nature of some of the issues raised. Students were also more willing to transition between groups as they had come to know each other better through reading these more personal reflections.

\section{What to Consider when Integrating Tablets into the Classroom}

Over the course of the experiment, we experienced many issues, both technological and pedagogical, that we needed to solve in order to effectively integrate tablets into our classes. These issues included device connectivity issues, the requirement to learn how to use both a new operating system and a new set of software applications, and deciding how best to make use of the tablet. Based on our experiences, we make the following six recommendations to any instructors interested in integrating tablets into their classrooms.

\section{1) Know "Everything" About the Tablet Operating System}

One of the main reasons we selected the iPad, rather than a competing tablet, was because we were already familiar with the iOS operating system from using iPods and iPhones. Although several of the students were also familiar with the operating system from using such products, most were not. It was therefore essential that we knew more than just the "basics" of how the operating system functioned. We needed detailed knowledge of the system menus and configurations, so that, in the event that a student did not understand what to do, we could quickly assist them. The students asked questions ranging from the simple, such as how to adjust the screen brightness, to the complex, such as how to synchronize email and calendar functions with their other devices. A few times, a student's iPad would not automatically connect to the university's wireless network; we therefore needed to be able to quickly reconfigure the iPad's Wi-Fi settings 
to make a connection possible - a fairly easy task for someone who knows what to do, but a task which is not obvious for someone who does not.

The students did not require a great deal of instruction in the use of the iPad. Some students needed to be instructed in how to download and install applications and how to navigate between applications. Many students did not have an iTunes account, which is necessary for downloading applications, so we had to assist them in creating one. But in general it was rare that students encountered technical problems with their iPads such as applications not loading, the iPad not syncing with their computer, or a lack of Internet connectivity. Nevertheless, when such problems did occur, it was imperative that we solved them quickly in order to maintain the students' confidence in the decision to adopt the technology.

Prior to implementing the use of iPads in our classes, we experimented with the technology for a couple of hours per week over the span of four months in order to ensure that we had detailed knowledge of all the workings of the technology. During that time we explored all the menus and settings, experimented with different applications to find ones which we felt were best, and intentionally tried to create problems with the software settings so that we could discover how to resolve issues should a student accidentally cause one to occur during their own exploration of the device. Both of us were "technologically savvy" prior to implementation of the pilot study; however, we found the menus and settings easy to understand and operate and have been able to teach other faculty at our institution about them without much difficulty. The routine problems that students encountered were wireless connectivity issues, trouble accessing email, and difficulty downloading and using the applications; the key knowledge/skills that an instructor should possess are the ability to reset the wireless settings, the ability to set up a "profile" including an email account and password on the device, and the ability to install applications on the tablet and demonstrate their use to the student.

\section{2) Decide Early On How You Would Like to Use the Tablet in Your Class}

Many of the activities for which the tablet can be used require the use of downloaded applications. However, you may find that there are many "similar" applications that will perform the same tasks. For example, when we decided to use the iPad to transmit lecture notes, we tested eight different applications for annotating lecture notes in a variety of formats, including pdf, the format that we ultimately selected. Different applications provided different functionality; for example, some did not provide the ability to handwrite over top of the document. We also tested a variety of applications for administering quizzes. At the launch of the experiment, we did not agree on a quizzing application, which is why one of us used a clicker-style application while the other used a learning management system to administer an online quiz. Ultimately, we were not satisfied with either approach, as programming a quiz through the learning management system is time consuming, and the quizzing application we experimented with, though easy to program, conflicted with our university's wireless network and so the quiz malfunctioned several times during the semester. We are both still actively searching for a quizzing application that would be superior to those methods; however, a web-based learning management system at present appears to be more reliable than a tablet based application.

Some of the applications we investigated needed to be purchased while others were provided for free. Because our experiment was a trial only, and the students would not keep the iPads at the end of the course, we specifically focused on finding good quality free applications, so that the students would not be out-of-pocket for software they might not use again. Nevertheless, given the already high cost of education, we still prefer to use free applications in order to minimize the cost for students. 
As was the case with the tablet's operating system, it is critically important to understand the complete functionality of each application that you intend to use in class. Because we spent several months becoming acquainted with the software we used in class, we were able to effectively demonstrate its use and assist students who experienced technical difficulties. The four months we spent experimenting with various applications helped us to identify applications which fit our needs quite well.

\section{3) Ensure that You Work Closely with Your Institution's Information Technology Department}

Throughout the project we encountered some technical difficulties including an inability to connect to the wireless network, difficulty sharing information between devices because of network restrictions, and the occasional incident where a student, while exploring the device's tools and properties, accidentally reconfigured their device so that it would no longer function in the way necessary for use in class. Fortunately, we were able to obtain assistance from our university's IT department to ensure that sufficient wireless bandwidth was made available. Although the technology was "new" to our IT department as well, they made a strong effort to help us to understand all of the technical details of the operating system and of the device to ensure that we possessed all necessary knowledge to conduct the trial and deal with minor technical issues such as connectivity or accidental reconfiguration.

During the course of the semester, many of the students also relied on the IT department for technical assistance between lectures when they could not ask us for technical assistance. It was therefore very important that the IT department was fully informed of the tablet usage and understood how to assist students with any technical difficulties they encountered. It was thus necessary for the IT department to provide support for the iOS operating system, something which they had not previously done. Working with the IT department provided great benefit, as several of their members were able to suggest applications for us to investigate and were able to help us explore the full functionality of the applications that we did choose.

\section{4) Make the Tablet an Integral Component of Your Class}

Structured use: In order for the students to fully perceive the benefits of using the tablet, they must remain actively engaged with the tablet on a regular basis. When adopting universal usage of a tablet in class, there are two main dangers to consider. First, if the tablet is not used often enough, students will perceive the tablet to have low useful value. Because the tablet operating system and application software will be unusual to many of the students, some students may resent having to learn how to use the new system. By fully integrating use of the tablet in a variety of aspects of your course, students see the benefit of learning to use the many features available on the tablet. If the tablet is used infrequently, then the students may adopt behaviors which minimize their own use of the device, using it only when necessary rather than fully exploring the device's potential.

Unstructured use: The second danger with adopting tablet technology is that the tablet may become a distraction for the students. It has been documented that students who use laptops in class often become distracted because they use the laptop for non-academic purposes during the lecture (Kay \& Lauricella, 2011a, 2011b; Young, 2010). While in many classes laptop usage is not universal, and hence the distraction problem is not universal, the potential for distraction when every single student possesses a tablet is greatly increased. Several features of the tablet can mitigate the distraction factor. We chose the iPad in part because the system only allows one application to be open at a time; users cannot "multitask" by having multiple files/software programs open simultaneously. However, Android and Blackberry devices do provide limited multitasking abilities. If students are not constantly engaged with the tablet for academic purposes during class, 
they may instead use it for non-academic purposes. The best tactic to prevent the tablet from becoming a distraction is to ensure that the students are constantly engaged with the tablet for academic purposes. We found that, because the students constantly used the iPads for reading and/or taking notes or for participating in class activities, they did not have many opportunities to use the tablets for non-academic purposes during the lecture time. The tablet was much less conducive to engaging in non-academic activities during lecture precisely because we structured our classes in such a way that the students were required to be actively using the iPad for academic purposes much of the time.

\section{5) Describe the Features and Benefits on the First Day}

As most of our students were young and quite technologically savvy, it did not take a great amount of "convincing" to get most students excited about using a tablet in class. Nevertheless, several of the students were apprehensive about being given a new technology that they had little experience in using; thus, introduced uncertainty into their learning environment. Providing a full explanation of the features of the tablet that will be used in class, as well as offering a discussion of the benefits associated with those features, will help to manage student expectations so that they can be confident that there is a useful purpose to adopting the technology beyond simply adopting it for technology's sake. Providing a complete description of how the tablet will be used can help to mollify any apprehension among the students and also serve as a guide to the students as to what your expectations are for their use of the device. Simple instructions such as, "You should have your lecture slides open on the screen so that you can follow along; you can make typed or handwritten notes directly on the tablet, or, if you prefer, you can also make notes on paper" set the type of behavior expected in class. We actually found that this instruction worked well as the students felt they were "supposed" to be keeping their lecture notes open on the screen to follow along, thus eliminating the use of the iPad for non-academic purposes during most parts of the class.

Describing the key features and benefits also demonstrates your own confidence in the technology to the students. Although many will be excited about using the tablets, they will still have questions. Offering a detailed discussion on the first day of class establishes you as an expert in the technology, which will reassure the students that, as they experience difficulties, you can easily assist them when needed. Because many of the students will have limited experience in using this technology, integrating tablets into your classroom will require teaching the students how to use the tablets, in addition to teaching them your main course content.

\section{6) Carefully Consider How to Distribute the Tablets}

Because our experiment lasted for only six weeks, and the students would not be using tablets in other courses, requiring students to purchase a tablet would have added a significant expense to attending the class. We thus decided to provide tablets to each student at no cost, on condition that they were returned in working condition at the end of the course. For others who are considering a pilot study, we do recommend that you consider the costs, to both the students and to your institution, of using tablets in class, when you are deciding who should pay for the device. In order for the students to fully realize the benefit of the device, and also for them to become accustomed to using it regularly, it is important that the students be allowed to take the device home with them to use. Even if your institution plans to retain ownership of the devices, we do not recommend distributing them and then collecting them each class for three reasons: first, assigning work requiring the use of the tablet outside of class will further help to engage the students academically with the device; second, some software applications will require a password or access to an email account, and having each student program a tablet at the beginning of each class and then deprogram it at the end before returning it would be time consuming and would place a 
higher burden on the instructor who would likely need to assist students individually with those tasks every time; and third, transporting the tablets to and from classrooms and storing them between classes would create another administrative burden for the institution. We recommend that students be allowed to keep their tablets to use for both academic and personal use, throughout the entire semester where they will be using them in class.

When considering whether to adopt tablet technology across an entire academic program, as we have now done following this successful pilot trial, we recommend that the institution order the tablets centrally. Depending on the manufacturer, the institution may be able to secure a price reduction, given the quantity of tablets that are to be ordered. More importantly, central ordering and distribution ensures that all students receive the same equipment prior to the start of the course. Many of the tablets are available in standard and upgraded or premium models. Instructors should carefully consider whether the standard model would be sufficient, or whether the added features of a premium model would be required. If a premium model is required, simply instructing students to purchase their own could potentially lead to situations where some students either mistakenly purchase the wrong model, or intentionally purchase a model with less functionality in order to save money, thus having a detrimental impact on their participation in the use of the tablet in class.

If the device is paid for, or partially paid for, by the institution, we recommend a minimum residency period, for example two semesters, before the student is afforded ownership of the device. If the student withdraws prior to completing the residency period, then the student should either return the device to the institution, or, so that the institution is not burdened by ownership of a used device, pay some portion of the cost of the device. If the students are required to pay the full cost of the device then that is not an issue. If the institution opts for central ordering and chooses a basic tablet model, we do recommend that institutions provide students with the option to purchase an upgraded model, with the student paying the difference in price, as some students may prefer the extra functionality.

One final issue to consider is what to do with students who lose or damage their tablet. If the tablet is an integral component of the class, it may be necessary to have back-up unit available to loan to the student until they can acquire a new tablet. If the tablet has been paid for or partially paid for by the institution, then consideration must be given to whether the student should be responsible for purchasing a new device, and serious consideration must especially be given to the potential situation where a student lacks the financial resources to purchase a replacement tablet on their own.

\section{Why a Tablet is not a Laptop Computer}

Tablets, such as the iPad, which we used, are not the same as laptop computers. They differ in design, functionality, and potential for both academic and social integration in a university classroom. While both are portable and provide the student with Internet access, we found that both types of devices provide unique advantages which the other cannot match.

A key advantage of a laptop computer is the higher functionally of the separate keyboard. Although keyboard attachments are now available for tablets, we did not make use of them in the pilot study for budgetary reasons, and we found that the requirement to type directly on the screen proved to be a large disadvantage of the tablet. As well, the functionality of the software on a laptop is much greater; despite the wide number of software applications available for a tablet such as an iPad, a computer is still preferred for writing formal reports, creating presentations, and working with spreadsheets, as a tablet's capabilities in these regards are limited. Third, laptop computers have a superior file management system, allowing files to be located from a central filing system and transferred easily from device to device. In contrast, an iPad lacks a central fil- 
ing system; rather, files are stored within applications and so cannot be located, previewed, or accessed without first opening the application. That fact makes it more difficult to locate files and very difficult to share content between applications, which would be necessary for embedding images, graphs/charts, or multimedia content in presentations and reports.

Nevertheless, the tablet does provide significant unique advantages over a laptop computer, which can lead to a better learning environment. First, tablets lack true "multitasking" capabilities; although they allow multiple applications to be running, they do not allow multiple applications to be viewed simultaneously. While this lack of functionality might at first seem like a negative aspect, it actually helped students to focus more on their lecture material and prevented them from becoming distracted by the simultaneous use of off-task software applications. At the beginning of the course, we asked students who had previously used laptops in class about their previous off-task usage during lectures. We also asked the same question of students at the end of the course regarding their off-task usage of the iPad. The results are presented in Table 1:

\begin{tabular}{|l|c|l|c|}
\hline \multicolumn{3}{|c|}{ Table 1: Off-Task Usage By Students During a Lecture } \\
\hline $\begin{array}{l}\text { \% Who Previously Used a Laptop for ... } \\
\text { (Prior to iPad Course) }\end{array}$ & \% Who Used the iPad for \\
\hline Personal Email & $80 \%$ & Personal Email & $61 \%$ \\
\hline Facebook & $84 \%$ & Facebook & $67 \%$ \\
\hline $\begin{array}{l}\text { MSN / Facebook } \\
\text { Messenger / Other } \\
\text { chat }\end{array}$ & $36 \%$ & $\begin{array}{l}\text { MSN / Facebook } \\
\text { Messenger / Other } \\
\text { chat }\end{array}$ & $0 \%$ \\
\hline YouTube & $42 \%$ & YouTube & $33 \%$ \\
\hline Twitter & $3 \%$ & Twitter & $6 \%$ \\
\hline
\end{tabular}

Use of personal email and social networking tools declined dramatically with the implementation of the iPad as students could not have both their lecture notes and a web-browser or chat window open simultaneously. A small decline in the percentage who watched YouTube videos instead of focusing on the lecture was also observed. This reduction in off-task device usage was a significant benefit of using the iPad rather than using a laptop computer.

An additional benefit of using the iPad for taking notes rather than using a laptop was found in the ability to handwrite information on the screen. For the Economics class, which required the use of mathematical equations and graphs, handwriting is a preferred method for inscribing information. Typing equations and creating graphs on a computer screen using a mouse or touchpad is incredibly cumbersome, and students who would previously type lecture notes on their laptops would still use a pen and paper to take additional notes. The tablet's ability to accept handwritten inputs, whether from using a fingertip or a stylus (a special pen for writing on the screen), was a unique advantage of the tablet over a laptop and allowed the students to record all of their lecture notes digitally, rather than relying on a mixture of electronic and paper notes. Because the students could take all their notes on the iPad, they did not need to carry additional notebooks.

Despite the more limited overall functionality of a tablet relative to a laptop computer, we believe that a tablet is a superior device for in-class usage. Tablets provide the same portability and connectivity that a laptop provides; however, their input mechanism allows for both typed and handwritten annotation which laptops do not. As well, the tablet reduces off-task usage during lecture, specifically the use of email and social networking applications, because the tablet does not permit users to view multiple applications simultaneously. 
The tablet is not a replacement for a personal computer; we found that students would still need a computer to complete coursework such as creating presentations and writing reports / essays. However, a laptop would not specifically be needed for those purposes, as a desktop computer would suffice. Rather, the tablet is an additional tool for students to use. We found that it was easier for students to capture all of their notes digitally on a tablet versus a laptop because of the tablet's ability to accept handwritten input.

As mentioned earlier, pre-course and post-course survey results were used to assess the success of the pilot courses. Measures of success included: students' adoption of tablets within the classroom setting, students' perceived enhancement of learning, and students' desire to enroll in other tablet format courses. At the beginning of these trial courses, $67 \%$ of the students indicated that they regularly brought a laptop to their other classes for the purpose of taking lecture notes. At the end of these courses, only $13 \%$ of students indicated that they were still bringing their laptop to every class which represented a significant change in behavior, a 54\% difference when compared to their pre-course behavior. A high percentage of the students $(78 \%)$ indicated that they were using the tablet for taking lecture notes. In addition, $96 \%$ of the students believed that the tablet had enhanced their learning, and $91 \%$ indicated that they would like to use one in their future courses. Although $43 \%$ of the students indicated that they felt they did not make full use of the device's features because they knew they had to return it at the end of the course, overall, both the students and ourselves preferred the use of tablets in class to the use of laptop computers.

\section{Concluding Remarks}

In this paper, we have described our experiences with integrating tablet technology in classrooms. In our case, we chose to use Apple iPads; however, there are many other tablets available that can perform the same functions. For tablets to be used effectively, they must be integrated into several aspects of the course. We recommend encouraging the students to use the tablet to view a set of lecture notes, and take additional notes if necessary, during the class. Doing so ensures that the students are constantly engaged with the device for academic purposes. However, simply using the tablet for reading or taking lecture notes greatly underutilizes the device and would not alone justify the adoption of the device in class. In addition, designing a series of activities that make use of the device's Internet connection, and the fact that students can use the device to share information and collaborate with one another, will help to enrich the students' learning experience. We have suggested a number of possible activities including having students perform research, read articles, debate, and work on group projects that require information sharing. We have found that such activities greatly increased the students' involvement in the course content and greatly increased their interactions with each other, relative to previous semesters where we had not used tablets.

Ultimately, when adopting a tablet in class, it is important that, as the instructor, you have a clear understanding of how you intend to use the technology in class, what types of software applications you would like to use, and how the operating system and applications function. Students will look to you as the "expert", so you must be prepared to answer any and all questions they might have, so that they can be confident that the adoption of tablet technology is a worthwhile endeavor. 


\section{References}

Apple can run to $\$ 510$ with iPad market share momentum. (2011, September 21). Forbes. Retrieved from: http://www.forbes.com/sites/greatspeculations/2011/09/21/apple-can-run-to-510-with-ipad-marketshare-momentum/

Banister, S. (2010). Integrating the iPod Touch in K-12 education: Visions and vices. Computers in the Schools, 27, 121-131.

Cismaru, R., \& Cismaru, M. (2011). Laptop use during class: A review of Canadian universities. Journal of College Teaching \& Learning, 10(11), 21-28.

Eichenlaub, N., Gabel, L., Jakubek, D., McCarthy, G., \& Wang, W. (2011, September). Project iPad: Investigating tablet integration in learning and libraries at Ryerson University. Computers In Libraries, 1721.

Franklin, T. (2011). Mobile learning: At the tipping point. Turkish Online Journal of Education Technology, 10(4), 261-275.

Fischman, J., \& Keller, J. (2011). College Tech goes mobile. Chronicle of Higher Education, 58(1), 50.

Gawelek, M. A., Spataro, M., \& Komarny, P. (2011). Mobile perspectives: On iPads why mobile? EDUCAUSE Review, 46(2), 28-32.

Goral, T. (2011, January). Take II Tablets. University Business, 46-49.

Kay, R. H., \& Lauricella, S. (2011a). Exploring the benefits and challenges of using laptop computers in higher education classrooms: A formative analysis. Canadian Journal of Learning and Technology, $37(1), 1-18$.

Kay, R. H., \& Lauricella, S. (2011b). Unstructured vs. structured use of laptops in higher education. Journal of Information Technology Education, 10, IIP33-IIP42. Retrieved from http://www.jite.org/documents/Vol10/JITEv10IIPp033-042Kay840.pdf

Kaya, T. (2010). Classroom iPad programs get a mixed response. Chronicle of Higher Education, 57(6), A8.

Keller, J. (2011). The slow-motion mobile campus. Chronicle of Higher Education, 57(36), B4-B6.

Murphy, G. D. (2011). Post-PC devices: A summary of early iPad technology adoption in tertiary environments. E-Journal of Business Education \& Scholarship of Teaching, 5(1), 18-32.

Percival, J., \& Percival, N. (2009). A case of a laptop learning campus: How do technology choices affect perceptions? ALT-J: Research in Learning Technology, 17(3), 173-186.

Schools release iPad studies. (2011, July/August). BizEd Magazine, 60-63.

Vuojärvi, H., Isomäki, H., \& Hynes, D. (2010). Domestication of a laptop on a wireless university campus: A case study. Australasian Journal of Educational Technology, 26(2), 250-267.

Weider, B. (2011). iPads could hinder teaching, professors say. Chronicle of Higher Education, 57(28), A22-A23.

University of Southern Mississippi to provide Samsung Galaxy Tab 10.1 Tablets to students. (2011). Retrieved from http://www.businesswire.com/news/home/20110801006060/en/University-SouthernMississippi-Provide-Samsung-Galaxy-Tab\%E2\%84\%A2

Young, J. R. (2010). A test for the iPad: Will it bring the Internet to the beanbag chair? Chronicle of Higher Education, 56(31), A14. 


\section{Biographies}

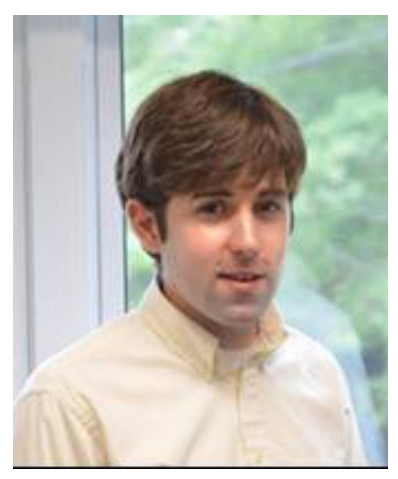

Colin F. Mang is a Lecturer (Business Administration) at the School of Business at Nipissing University where he teaches courses in Statistics and Economics. His primary research focuses on the millennial generation, to which he belongs, and includes consumer attitudes towards new technologies, perceptions of ethical business practices among young adults, and the impact of university education on individual attitudes towards business and on future labor market experiences.

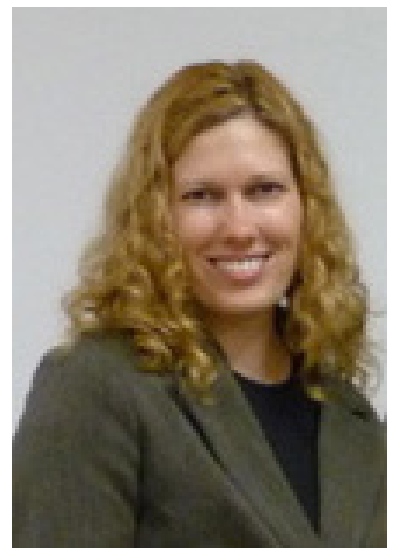

Leslie J. Wardley is a Part-time Instructor in Nipissing University's Faculty of Applied and Professional Studies (School of Business) where she teaches courses in administration and organizational studies. Her professional background includes university administration and small business management with a focus in project management and veterinary medicine. Her research has explored culture and diversity, ethics, university student satisfaction and organizational development and change. 